\title{
Labour in women with gestational diabetes mellitus
}

\author{
Klaudia Grabowska, Angelika Stapińska-Syniec, Aleksandra Saletra, \\ Patrycja Jarmużek, Dorota Bomba-Opoń \\ ${ }^{1 \text { st }}$ Department of Obstetrics and Gynaecology, Medical University of Warsaw, Poland
}

\begin{abstract}
Objectives: Gestational diabetes mellitus (GDM) constitutes one of the most common pregnancy complications and affects $3-5 \%$ of all pregnancies, with its incidence still growing. Due to possible maternal and fetal complications, the peripartum management of GDM patients continues to be a debatable issue. The aim of the study was to analyse the course and final way of delivery in women with gestational diabetes mellitus. The effectiveness of induction of labour (IOL) was also assessed and factors predisposing to cesarean section were identified.

Material and methods: The study group consisted of 204 women with GDM who delivered in the Academic Centre for Woman's and Neonate's Health in Warsaw over the years 2013 and 2014. The indications and ratios of elective and intrapartum cesarean sections were analysed. Patients qualified for induction of labour were compared depending on their final way of delivery.

Results: Over a half of all deliveries in the study group (53\%) were cesarean sections. Elective surgeries accounted for $70 \%$ of all cesarean sections, predominantly due to a history of previous operational deliveries. Only $12 \%$ of the study group developed spontaneous uterine contractions and delivered vaginally. A comparison of the vaginal delivery group $(n=96)$ with cesarean section group $(n=108)$ pointed to high pregestational BMI value and advanced maternal age as factors increasing the patient's risk for surgical delivery ( $p=0.0000$ and $p=0.048$ accordingly). The comparison of women undergoing $\mathrm{IOL}$ vs. omen with spontaneous uterine contractions showed no increase in the ratio of intrapartum cesarean sections in the IOL group - in both subgroups vaginal delivery was achieved in $75 \%$ of cases.

Conclusions: Patients with GDM are more likely to undergo cesarean section, but the implementation of induction of labour at term does not further aggravate this risk. Major risk factors for operational delivery in GDM population included: advanced maternal age, high pregestational BMI value and undergoing insulin therapy.
\end{abstract}

Key words: GDM, induction of labour, gestational diabetes mellitus

Ginekologia Polska 2017; 88, 2: 81-86

\section{INTRODUCTION}

Gestational diabetes mellitus (GDM) is defined as any degree of glucose intolerance with onset or first recognition during pregnancy [1]. This condition constitutes one of the most common obstetric complications and is estimated to affect as many as $3-5 \%$ of all pregnancies in the Caucasian population [2-6]. The growing incidence of this phenomenon is attributed mainly to large prevalence of risk factors for developing diabetes among women of reproductive age - obesity, insulin resistance, hypertension and pregnancy in women over 35 years old in particular [7]. Moreover, the introduction of modified diagnostic criteria for GDM in oral glucose tolerance test (OGTT) in 2014 is also likely to contribute to an increased prevalence of gestation diabetes [8].
Consequences stemming from maternal hyperglycaemia can be divided into short-term (that is, affecting the course of pregnancy and puerperium) and long-term, taking their toll on the future health of the mother and child. Increased risk for peripartum haemorrhage, severe perineal tears and caesarean section constitute some of the short-term maternal complications, while the newborns are faced with a higher probability of developing macrosomia, hyperinsulinaemia and postpartum hypoglycaemia. Macrosomia itself (defined differently by various authors, most commonly as fetal mass $>4350 \mathrm{~g}$ or disparity between head circumference and abdominal circumference of over $4 \mathrm{~cm}$ ) is known to lead to shoulder dystocia, intrapartum clavicular fracture and potentially irreversible brachial plexus damage. 
Even though gestational diabetes alone is not considered an indication for elective caesarean section, the increased prevalence of fetal macrosomia (stemming from the fetus' altered head-to-waist proportions) contributes to the fact that afflicted women bear a much higher risk for surgical delivery than general population $[9,10]$.

Up to date, there is no consensus as to whether it is possible to bypass the consequences of maternal hyperglycaemia by implementing adequate peripartum management (optimal term and way of delivery). Whether or not elective induction of labour at term in women with GDM is justified and effective in preventing macrosomia is a particularly discussed issue [1].

\section{OBJECTIVES}

In our study we set out to evaluate the effectiveness of induction of labour and the course of labour in women with gestational diabetes mellitus. We also attempted to identify risk factors for surgical delivery in the studied populations.

\section{MATERIAL AND METHODS}

The study group consisted of 204 pregnant women diagnosed with gestational diabetes mellitus who underwent labour in the University Centre for Woman's and Newborn's Health of Medical University of Warsaw between the years of 2013-2014. The patients were diagnosed according to Polish Gynaecological Society criteria of 2011 [12], that is when their fasting plasma glucose (FPG) was above $125 \mathrm{mg} / \mathrm{dL}$ twice in a row or an abnormal glucose tolerance in oral glucose tolerance test (OGTT) with $75 \mathrm{~g}$ glucose was detected (fasting plasma glucose equal to or higher than $100 \mathrm{mg} / \mathrm{dL}$, plasma glucose equal to or higher than $180 \mathrm{mg} / \mathrm{dL}$ one hour and/or $140 \mathrm{mg} / \mathrm{dL}$ two hours after drinking glucose solution). Women with twin pregnancies and suffering from pregestational diabetes mellitus (PGDM) were excluded from the study.

The study group included women in singleton pregnancy. Maternal age fluctuated between 23 and 42 years old, with a mean value of 32 years, while $35 \%$ of all patients were 35 years old or older. BMI value ranged between 15-42, with a mean value of $25 \mathrm{~kg} / \mathrm{m}^{2}$. BMI of over $27 \mathrm{~kg} / \mathrm{m}^{2}$ was observed in $31 \%$ of the patients. The median of gestational weight gain equaled $10 \mathrm{~kg}$ (from minus $5 \mathrm{~kg}$ to $27 \mathrm{~kg}$ ). Gestational age was confirmed with ultrasound examination during the first trimester in every patient. A great majority (95\%) of women were diagnosed with GDM between $24^{\text {th }}$ and $28^{\text {th }}$ gestational week. Multiparas accounted for $60 \%$ of the study group. Nearly one third of them (30\%) already had a history of GDM in previous pregnancies. In four fifths of the patients (80.4\%) dietary management was sufficient to ensure normoglycaemia, while insulin therapy had to be implemented in $15 \%$ of cases. Every twentieth (4.6\%) patient admitted to not have been following their doctor's dietary instructions.

In $49 \%$ of patients clinical problems other than GDM occurred during the pregnancy. Predominant complications included: upper respiratory tract infections and bacterial/candida vaginitis (34\% altogether), as well as urinary tract infections (17\%), preterm delivery (14\%), pregnancy induced hypertension (14\%). Cholestasis of pregnancy was observed in $12 \%$, lower limb oedema in $6 \%$ and preeclampsia in $3 \%$ of patients with additional complications. 17 women had a history of infertility treatment. Fetal congenital anomalies were observed in 2 cases: 1 case of diaphragmatic hernia treated in utero with FETO procedure and one case of ventricular sept defect (VS.D). Intruterine growth restriction (IUGR) was observed in $5.4 \%$ of fetuses $(n=11) .2 .5 \%$ of all fetuses were hypertrophic, defined as LGA (> 90 pc).

$49 \%$ of the study group suffered from chronic diseases, predominantly hypothyroidism due to Hashimoto disease, obesity, chronic hypertension and asthma (in 33, 9, 7 and 6 patients accordingly). Some of the less common diagnoses included: sclerosis multiplex, hypophosphatemic rickets, Wilson's disease, hyperthyroidism, nicotinism.

A substantial percentage of the study group required induction of labour. The criteria for the procedure in a vast majority of cases included gestational age (after excluding cephalopelvic disproportion). In our center IOL was routinely performed in women diagnosed with GDM who have completed $40^{\text {th }}$ week of gestation or in women with GDM and LGA who have completed $39^{\text {th }}$ week of gestation. Overall $47 \%(n=96)$ of all women viable for an attempt at vaginal delivery were qualified for preinduction and/or induction procedures. $57.7 \%$ of them underwent preinduction $(55.9 \%$ with the help of Foley catheter, $1.8 \%$ with Prepidil gel), which in $9.9 \%$ of cases was sufficient for eliciting labour. Main strategies of induction, on the other hand, included intravenous oxytocin administration with (40.5\%) or without (39.6\%) following amniotomy.

A database of women with gestational diabetes mellitus was analysed retrospectively and the percentages and indications for elective caesarean sections were determined. In the group of patients viable for an attempt at vaginal delivery a subgroup of patients qualified for induction of labour and a subgroup of women with spontaneous uterine contractions was distinguished. The odds for surgical delivery and ratio of successful vaginal childbirths was then compared in the two mentioned subgroups.

The data was analysed with the help of Microsoft Excel 2013 and statistical programme STATISTICA 12. Shapiro-Wilk and Wilkinson tests were conducted to check the resemblance of the given variable distribution to the normal distribution. Percentages and arithmetic means were calculated for each parameter. Calculations for qualitative variables 
were carried out by Pearson test or the precise Fisher test. For the qualitative variables, t-Student and U Mann-Withney tests were conducted. The level of statistical relevance was acknowledged by the $p$ value of $p<0.05$.

\section{RESULTS}

The analysis of the way of delivery in the whole study group (204 patients) revealed that $47 \%$ of patients delivered vaginally, while caesarean section was performed in $53 \%$ cases. In the subpopulation of patients receiving only dietary management (GDM1) vaginal delivery constituted $50 \%$ of all labours, while the other half required surgical intervention. As for the women receiving insulin therapy (GDM2), only $30 \%$ of them gave vaginal birth and as many $70 \%$ qualified for caesarean section.

A vast majority of vaginal deliveries was accomplished only after induction of labour. Only $12 \%$ of patients developed spontaneous uterine contractions that led to vaginal delivery, whereas almost three times more patients (35\%) required at least one means of preinduction and/or induction or labour (Fig. 1).
As many as $37 \%$ of patients were initially disqualified from an attempt at vaginal delivery. Among the performed caesarean sections - which constituted $53 \%$ of deliveries altogether -7 out of 10 were elective laparotomies. Intrapartum caesarean sections after failed vaginal delivery attempt constituted only $16 \%$ of all deliveries (Fig. 1).

Prevalent indications for elective caesarean section included: history of at least one caesarean section (51\%), breech position of the fetus (9\%), placental abruption and placenta praevia (10\%), fetal macrosomia (7\%), preeclampsia (2\%) and a large group of other, non-obstetric indications (21\%). Lack of progression in the first and rarely in the second stage of labour (67\%) and imminent fetal asphyxia (33\%) accounted for cases of intrapartum caesarean sections (after failed vaginal delivery attempt).

In order to identify the factors that may increase the risk for operational delivery, the groups of women succeeding in vaginal delivery $(n=96)$ and women undergoing caesarean section $(n=108)$ were compared. The results of this analysis are depicted in table below (Tab. 1). The comparison has revealed that - in relation to vaginal delivery

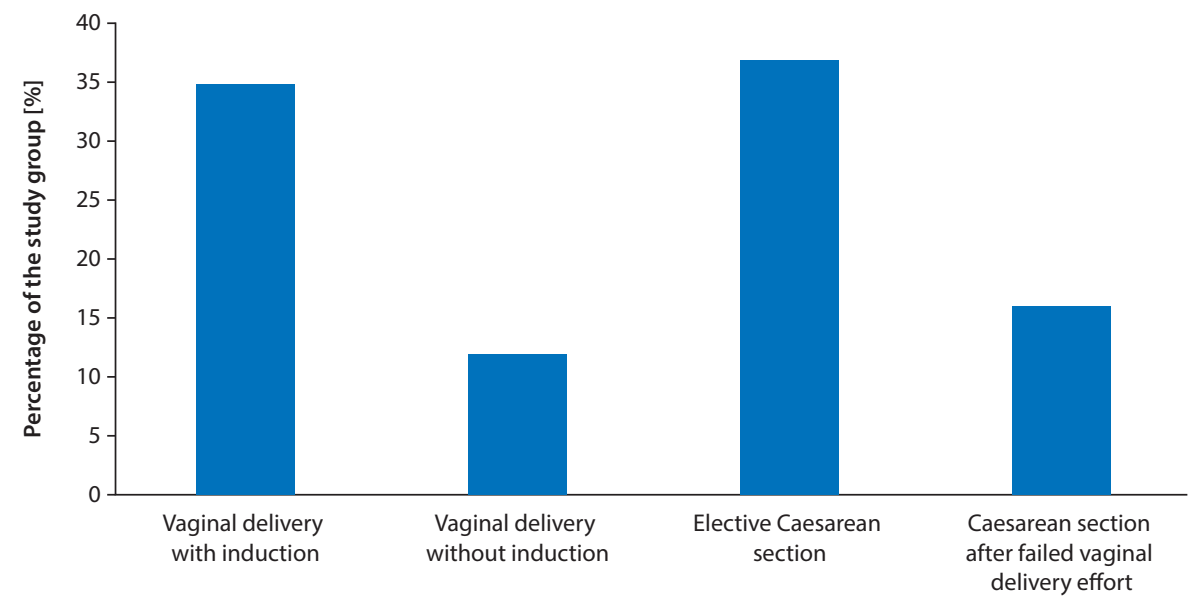

Figure 1. Ways of delivery in the study group

Table 1. Characteristics of patients depending on the way of delivery

\begin{tabular}{|l|c|c|c|}
\hline Feature & $\begin{array}{c}\text { Vaginal delivery group } \\
(\mathbf{n = 9 6 )}\end{array}$ & $\begin{array}{c}\text { Ceasarean section group } \\
(\mathbf{n = 1 0 8 )}\end{array}$ & $\mathbf{p}$ value \\
\hline Age $[$ years] & $\mathbf{3 2 . 2}$ & $\mathbf{3 3 . 4}$ & $\mathbf{p}=\mathbf{0 . 0 4 8}$ \\
\hline BMI $\left[\mathbf{k g} / \mathbf{m}^{2}\right]$ & $\mathbf{2 3 . 3}$ & $\mathbf{2 6 . 6}$ & $\mathbf{p}=\mathbf{0 . 0 0 0}$ \\
\hline Gestational weight gain $[\mathrm{kg}]$ & 9.88 & 10.97 & $\mathrm{P}=0.098$ \\
\hline Percentage of primiparas [\%] & 44.8 & 48.1 & $\mathrm{p}=0.631$ \\
\hline Gestational week at delivery & 38.2 & 37.6 & $\mathrm{p}=0.246$ \\
\hline Premature birth $<37$ gest.week [\%] & 9.4 & 8.3 & $\mathrm{p}=0.794$ \\
\hline Neonatal weight $[\mathrm{g}]$ & 3239.7 & 3285.0 & $\mathrm{p}=0.681$ \\
\hline Ponderal index $\left[\mathrm{kg} / \mathrm{m}^{3}\right]$ & 2.047 & 2.034 & $\mathrm{p}=0.592$ \\
\hline Macrosomia and $[\mathrm{GA}[\mathrm{n}]$ & 0 & 5 & $\mathrm{p}=0.643$ \\
\hline
\end{tabular}


Table 2. Comparison of patients undergoing preinduction and/or induction of labour with patients with spontaneous uterine contractions

\begin{tabular}{|l|c|c|c|}
\hline Feature & $\begin{array}{c}\text { Spontaneous uterine contractions } \\
(\mathbf{n = 3 2 )}\end{array}$ & $\begin{array}{c}\text { Induction of labour } \\
(\mathbf{n = 9 6 )}\end{array}$ & $\mathbf{p}$ value \\
\hline Age $[\mathrm{years}]$ & 32.7 & 32.4 & $\mathrm{p}=0.393$ \\
\hline BMI $\left[\mathrm{kg} / \mathrm{m}^{2}\right]$ & 24.0 & 24.6 & $\mathrm{p}=0.990$ \\
\hline Percentage of primiparas [\%] & 43.8 & 55.9 & $\mathrm{p}=0.220$ \\
\hline Week of delivery [hbd] & 37.2 & 38.5 & $\mathrm{p}=0.258$ \\
\hline Premature birth $<37$ gest.week [\%] & 28.1 & 11.7 & $\mathrm{p}=0.025$ \\
\hline Vaginal delivery percentage [\%] & $\mathbf{7 5}$ & $\mathbf{7 5}$ & $\mathbf{p}=\mathbf{0 . 6 0 0}$ \\
\hline Neonatal weight $[\mathbf{g}]$ & $\mathbf{3 0 4 0 . 3}$ & $\mathbf{3 3 0 5 . 5}$ & $\mathbf{p}=\mathbf{0 . 0 1 9}$ \\
\hline Ponderal Index $\left[\mathrm{kg} / \mathrm{m}^{3}\right]$ & 2.040 & 2.046 & $\mathrm{p}=0.081$ \\
\hline Mean duaration of the first stage of labour [min] & 275.91 & 266.94 & $\mathrm{p}=0.818$ \\
\hline Epidural analgesia [\%] & $\mathbf{2 9}$ & $\mathbf{7 1}$ & $\mathbf{p}=\mathbf{0 . 0 0 0}$ \\
\hline
\end{tabular}

group - the patients undergoing caesarean section were characterised by older maternal age (33.4 vs. 32.3 years) and higher pregestational BMI value ( 26.6 vs. $23.3 \mathrm{~kg} / \mathrm{m}^{2}$ ), and the obtained differences were statistically significant $(p<0.05)$ Other parameters taken into consideration showed no statistically significant differences between the two compared populations (Tab. 1).

The clinical value and effectiveness of induction of labour in the group of patients with gestational diabetes mellitus was evaluated by comparing maternal and neonatal parameters in two populations: women who underwent preinduction and/or induction of labour and not induced women (Tab. 2).

A higher percentage of primiparas and more advanced gestational week at delivery were noted in a group of patients who underwent induction of labour in reference to a group of patient with spontaneous uterine contractions (55.9\% vs. $43.8 \% ; 38.5$ hbd vs. 37.2 hbd accordingly). However, this data showed no statistical significance. Moreover, the occurance of preterm delivery was almost two-and-a-half times higher in a population without induction of labour (28.1\% vs. $11.7 \%)$. Neonates of women undergoing induction weighted approximately $300 \mathrm{~g}$ more at birth than neonates of not induced women (3305.5g vs. 3040, $3 \mathrm{~g}$; $\mathrm{p}<0.05$ ). The induced population requested for epidural analgesia two-and-a-half times more often ( $71 \%$ vs. $29 \%$; $p<0.05)$ than women with spontaneous contractions. Both of the forementioned features bore statistical significance. Finally, the induction of labour proved to have shortened the duration of the first stage of labour by more than 10 minutes (275.91 min vs. $266.94 \mathrm{~min}$ ) (Tab. 2).

The most crucial parameter to the analysis was the percentage of successful vaginal deliveries in both groups. The ratio of vaginal deliveries' accomplished in the group of induced women in comparison with the ratio of vaginal deliveries` in the no-induction group was to answer the question whether induction of labour increased the risk of caesarean section in the population of women with gestational diabetes mellitus. As the data collected in table no 5 indicate, the percentage of vaginal delivery was identical in both groups $-75 \%$ of women undergoing induction of labour, as well as $75 \%$ of women with spontaneous uterine contractions delivered vaginally, while the remaining $25 \%$ were qualified for intrapartum laparotomy. Therefore the performance of preinduction and/or procedures did not increase the risk of caesarean section in the population of women with GDM.

Fetal hypertrophy (LGA > 90 pc.) was diagnosed in $2.5 \%$ of fetuses $(n=5)$. A vast majority of newborns were born in good condition (defined as Apgar score in the fifth minute above or equal 8). In 8 newborns (2 delivered vaginally, 6 through caesarean section) Apgar score in fifth minute was lower than 8 . Nine newborns (4 delivered vaginally and 5 through laparotomy) required immediate intubation due to respiratory failure. In the whole group not a single case of shoulder dystocia or long bone fracture was observed.

\section{DISCUSSION}

Gestational diabetes mellitus continues to pose a substantial threat to both the mother's and child's health. Due to its growing incidence and possibility of severe peripartum complications, the optimal time and way of delivery in GDM is broadly discussed in literature.

Different authors present contradictory data concerning the rate of caesarean section in GDM patients. Ovesen et al. (2015) has recently published results of a research on a group of 9014 GDM patients among whom the overall rate of performed caesarean sections was 31\% [13]; on the contrary, the percentage of surgical deliveries obtained from Wei et al's. study of 2014 is essentially identical as in our study (52.7\% vs. 53\%) [14]. We has also observed statistically significant differences between caesarean section ratio in 
a group of patients with untreated GDM (59.7\%) with regard to treated gestational diabetes (48.4\%) and control group of women with normal glucose tolerance (47.6\%). The cited study was retrospective and limited to GDM defined as FPG $>4.4 \mathrm{mmol} / \mathrm{L}$ [14]. Our study has shown a prevalence of surgical deliveries in comparison to vaginal deliveries in a ratio $53 \%$ to $47 \%$. This imbalance was even more accentuated in the subpopulation of patients receiving insulin therapy (7 out of 10 patients delivered via caesarean section). It is worth mentioning, however, that $70 \%$ of all the performed laparotomies were elective procedures, many of them associated with the presence of non-obstetrical chronic diseases and risk factors. The most common indications for elective caesarean section in our study included: lack of the patient's consent for a vaginal delivery attempt after one caesarean section in the past or a history of at least two caesarean sections in the previous pregnancies (49\% of all elective indications). Interestingly, a typical indication for elective surgical intervention in gestational diabetes pregnancies according to Polish Gynaecological Society's reccomendations [15], which is fetal macrosomia, was observed in only a small percentage of patients $(2.5 \%$, $n=5$ ). Our study has identified high maternal pregestational $\mathrm{BMI}$ value and advanced maternal age to be the strongest predictors for caesarean section as final way of delivery.

Various publications provide ambiguous data as to whether elective induction of labour at term is an effective means to reducing the incidence of fetal macrosomia and serious endpoint such as shoulder dystocia. The opponents of this strategy point to an increase in risk of instrumental or surgical intervention after implementation of these procedures $[1,16]$. A big metaanalysis and systematic review from 2013 has shown, however, that in women with unruptured membranes induction of labour at term was associated with fewer surgical interventions [17]. Studies carried out by Caughey et al. (2009) and Wood et al. (2014) were even more optimistic and argued that induction is in fact a procedure reducing the risk of caesarean section $[16,17]$. Baslando suggested that results obtained for induction in general might not be applicable for a population of patients with GDM, as his study has shown a significantly higher rate of caesarean sections in women with GDM undergoing induction in relation to women without glucose metabolism disorder undergoing the same procedures [1].

Optimal time for induction of labour is another disputable issue. A number of studies advocating superiority of active management of peripartum period in women with GDM suggested $38^{\text {th }}$ week as the most favourable time to perform induction and preinduction in terms of neonatal complications [18-21]. Due to existing data that elective induction of labour in patients with mild GDM does not increase the risk of caesarean section until the end of the $40^{\text {th }}$ gestational week, the most common recommendation is to perform induction on qualified patients between $38^{\text {th }}$ and $40^{\text {th }}$ gestational week $[11,22]$. The importance of careful planning of this procedure was stressed in one of the studies that showed that delaying induction until after $41^{\text {st }}$ gestational week has tripled the risk of caesarean section when compared to induction in $39^{\text {th }}$ week [16].

A new randomised study by Boulvain has recently emphasized the positive outcomes of elective induction of labour in women with GDM between $37^{\text {th }}$ and $39^{\text {th }}$ gestational week. According to its authors, not only did performing induction during this period of time lead to fewer cases of shoulder dystocia and long bone fractured in newborns, but it also improved the chances for vaginal delivery and had no impact whatsoever on the risk of intrapartum caesarean section [11].

In 2011 a protocol for a prospective randomised trial GINEXMAL aiming to evaluate the effectiveness of induction of labour between $38^{\text {th }}$ and $39^{\text {th }}$ week of gestation as means to reducing the risk of caesarean section was published. It will provide the much needed, possibly deifinitive information on induction's impact on maternal and neonatal complications during partum [23].

\section{CONCLUSIONS}

The most important risk factors for surgical delivery in the population of women with GDM include advanced maternal age and increased pregestational BMI value. Our study has shown that elective induction of labour does not increase the risk for caesarean section in this group of patients and constitutes a safe and effective peripartum management strategy.

\section{REFERENCES}

1. Bas-Lando M, Srebnik N, Farkash R, et al. Elective induction of labor in women with gestational diabetes mellitus: an intervention that modifies the risk of cesarean section. Arch Gynecol Obstet. 2014; 290(5): 905-912, doi: 10.1007/s00404-014-3313-6, indexed in Pubmed: 24973018.

2. DeSisto $C L$, Kim SY, Sharma AJ. Prevalence estimates of gestational diabetes mellitus in the United States, Pregnancy Risk Assessment Monitoring System (PRAMS), 2007-2010. Prev Chronic Dis. 2014; 11: E104, doi: 10.5888/pcd11.130415, indexed in Pubmed: 24945238.

3. Schneider $S$, Bock $C$, Wetzel $M$, et al. The prevalence of gestational diabetes in advanced economies. J Perinat Med. 2012; 40(5): 511-520, indexed in Pubmed: 23120759.

4. Wójcikowski C, Królikowska B, Konarzewska J, et al. The prevalence of gestational diabetes mellitus in Polish population. Ginekol Pol. 2002; 73(10): 811-816, indexed in Pubmed: 12619313.

5. Kleinwechter H, Schäfer-Graf U, Bührer $\mathrm{C}$, et al. Gestational Diabetes Mellitus (GDM) Diagnosis, Therapy and Follow-Up Care. Experimental and Clinical Endocrinology \& Diabetes. 2014; 122(07): 395-405, doi: 10.1055/s-0034-1366412.

6. Lawrence JM, Contreras R, Chen W, et al. Trends in the prevalence of preexisting diabetes and gestational diabetes mellitus among a racially/ethnically diverse population of pregnant women, 1999-2005. Diabetes Care. 2008; 31(5): 899-904, doi: 10.2337/dc07-2345, indexed in Pubmed: 18223030.

7. Kinalski M, Śledziewski A, Kuźmicki M, et al. Wskaźniki ryzyka ujawnienia się cukrzycy ciężarnych. Diabetologia Praktyczna. 2003; 4(4): 257-263.

8. Flack JR, Ross GP, Ho S, et al. Recommended changes to diagnostic criteria for gestational diabetes: impact on workload. Aust N Z J Obstet 
Gynaecol. 2010; 50(5):439-443, doi: 10.1111/j.1479-828X.2010.01218.x, indexed in Pubmed: 21039377.

9. Gorgal R, Gonçalves E, Barros M, et al. Gestational diabetes mellitus: a risk factor for non-elective cesarean section. J Obstet Gynaecol Res. 2012; 38(1): 154-159, doi: 10.1111/j.1447-0756.2011.01659.x, indexed in Pubmed: 21995455.

10. Srichumchit $S$, Luewan $S$, Tongsong T. Outcomes of pregnancy with gestational diabetes mellitus. Int J Gynaecol Obstet. 2015; 131(3): 251-254, doi: 10.1016/j.ijgo.2015.05.033, indexed in Pubmed: 26372349.

11. Boulvain M, Senat MV, Perrotin F, et al. Groupe de Recherche en Obstétrique et Gynécologie (GROG). Induction of labour versus expectant management for large-for-date fetuses: a randomised controlled trial. Lancet. 2015;385(9987): 2600-2605, doi: 10.1016/S0140-6736(14)619048, indexed in Pubmed: 25863654.

12. Wender-Ozegowska E, Bomba-Opoń D, Brazert J, et al. Polish Gynecological Society. [Polish Gynecological Society standards of medical care in management of women with diabetes]. Ginekol Pol. 2011; 82(6): 474-479, indexed in Pubmed: 21853941

13. Ovesen PG, Jensen DM, Damm P, et al. Maternal and neonatal outcomes in pregnancies complicated by gestational diabetes. a nation-wide study. J Matern Fetal Neonatal Med. 2015; 28(14): 1720-1724, doi: 10.3109/14767058.2014.966677, indexed in Pubmed: 25228278.

14. Wei YM, Yang HX, Zhu WW, et al. Effects of intervention to mild GDM on outcomes. J Matern Fetal Neonatal Med. 2015; 28(8): 928-931, doi: 10.3109/14767058.2014.937697, indexed in Pubmed: 25068946.

15. Wender-Ozegowska E, Bomba-Opoń D, Brazert J, et al. Actualisation of Polish Gyneacological Society standards of medical care in management of women with diabetes. Ginekol Pol. 2014; 85(6): 476-478, indexed in Pubmed: 25029816.
16. Caughey AB, Sundaram V, Kaimal AJ, et al. Systematic review: elective induction of labor versus expectant management of pregnancy. Ann Intern Med. 2009; 151(4): 252-63, W53, indexed in Pubmed: 19687492.

17. Wood S, Cooper S, Ross S. Does induction of labour increase the risk of caesarean section? A systematic review and meta-analysis of trials in women with intact membranes. BJOG. 2014; 121(6): 674-685, doi: 10.1111/1471-0528.12328, indexed in Pubmed: 23834460.

18. Kjos SL, Henry OA, Montoro M, et al. Insulin-requiring diabetes in pregnancy: a randomized trial of active induction of labor and expectant management. Am J Obstet Gynecol. 1993; 169(3): 611-615, indexed in Pubmed: 8372870.

19. Witkop CT, Neale D, Wilson LM, et al. Active compared with expectant delivery management in women with gestational diabetes: a systematic review. Obstet Gynecol. 2009; 113(1): 206-217, doi: 10.1097/AOG.0b013e31818db36f, indexed in Pubmed: 19104376.

20. Niu B, Lee VR, Cheng YW, et al. What is the optimal gestational age for women with gestational diabetes type A1 to deliver? Am J Obstet Gynecol. 2014; 211(4):418.e1-e6, doi: 10.1016/j.ajog.2014.06.015, indexed in Pubmed: 24912097.

21. Gülmezoglu AM, Crowther CA, Middleton P, et al. Induction of labour for improving birth outcomes for women at or beyond term. Cochrane Database Syst Rev. 2012; 6: CD004945.

22. Vilchez GA, Dai J, Hoyos LR, et al. Labor and neonatal outcomes after term induction of labor in gestational diabetes. J Perinatol. 2015; 35(11): 924-929, doi: 10.1038/jp.2015.103, indexed in Pubmed: 26313053.

23. Maso G, Alberico S, Wiesenfeld U, et al. "GINEXMAL RCT: Induction of labour versus expectant management in gestational diabetes pregnancies". BMC Pregnancy and Childbirth. 2011; 11(1), doi: 10.1186/14712393-11-31. 